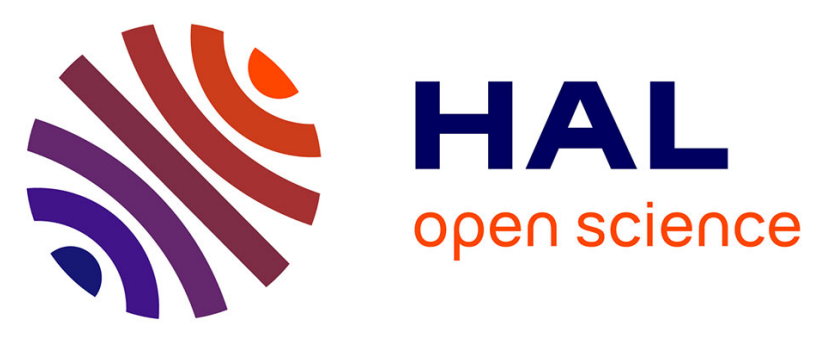

\title{
Polymer adhesive surface as flexible generic platform for multiplexed assays biochip production.
}

Céline A. Mandon, Ophélie I. Berthuy, Benjamin Corgier, Gaelle C. Le Goff, Patrice Faure, Patrice Marche, Loic Blum, Christophe A. Marquette

\section{To cite this version:}

Céline A. Mandon, Ophélie I. Berthuy, Benjamin Corgier, Gaelle C. Le Goff, Patrice Faure, et al.. Polymer adhesive surface as flexible generic platform for multiplexed assays biochip production.. Biosensors and Bioelectronics, 2013, 39 (1), pp.37-43. 10.1016/j.bios.2012.06.024 . inserm-00718337

\section{HAL Id: inserm-00718337 https://www.hal.inserm.fr/inserm-00718337}

Submitted on 16 Jul 2012

HAL is a multi-disciplinary open access archive for the deposit and dissemination of scientific research documents, whether they are published or not. The documents may come from teaching and research institutions in France or abroad, or from public or private research centers.
L'archive ouverte pluridisciplinaire $\mathbf{H A L}$, est destinée au dépôt et à la diffusion de documents scientifiques de niveau recherche, publiés ou non, émanant des établissements d'enseignement et de recherche français ou étrangers, des laboratoires publics ou privés. 


\title{
Polymer adhesive surface as flexible generic platform for multiplexed assays biochip production
}

\author{
Céline A. Mandon ${ }^{1}$, Ophélie I. Berthuy ${ }^{1}$, Benjamin P. Corgier ${ }^{2}$, Gaelle C. Le Goff ${ }^{1}$, Patrice \\ Faure $^{3}$, Patrice N. Marche ${ }^{4}$, Loïc J. Blum ${ }^{1}$ and Christophe A. Marquette ${ }^{1 *}$ \\ 1 Laboratoire de Génie Enzymatique, Membranes Biomimétiques et Assemblages Supramoléculaires, Institut \\ de Chimie et Biochimie Moléculaires et Supramoléculaires, Université Claude Bernard Lyon 1 - University \\ of Lyon - CNRS 5246 ICBMS, Bât. CPE - 43 Bd du 11 Nov. 1918, 69622 Villeurbanne, France. \\ 2 AXO Science, 34 du Mail, 69004 Lyon, France \\ INSERM U1042, Université Joseph Fourier Genoble1, HP2, Pole de Biologie CHU-Grenoble, 38706 La \\ Tronche, France \\ 4 INSERM U823, Université Joseph Fourier Genoble1, IAPC, 38042 Grenoble, France \\ Corresponding author: \\ E-mail: christophe.marquette@univ-lyon1.fr; Fax: +334 724479 70; Tel: +334 72431369
}

\begin{abstract}
The present report describes the integration and application possibilities of a new microarray concept based on adhesive surface. The method was shown to enable the straightforward production of 384 and 1536-well plates modified with 100 and 25 spots per well, respectively. Such in-well densities were only possible thanks to the fabrication process which implies first the deposition of the microarray on a flat adhesive surface and then its assembly with bottomless 384 or 1536 -well plates.

The concept was also confronted to various applications such as oligonucleotide detection, localised cell culture onto spotted adhesion proteins and immobilisation of peptide or active antibodies for immunoassays. In the particular case of immunotesting, the study focused on liver diseases diagnosis and more particularly on the detection of either one liver cancer marker, the alpha-fetoprotein, or the detection of Hepatitis C Virus infection. In every cases, interesting performances were obtained directly in crude patient serum, proof of the robust and generic aspect of the platform.
\end{abstract}

Keywords: Adhesive surface; AFP; Colorimetry; HCV; Localised cell culture; Microarray; Multiplexed assays

\section{Introduction}

Microarrays and microfluidics developments have been exponential since the beginning of the century with the achievement of rapid soft lithography prototyping and the democratisation of in-lab microarray spotting (Whitesides 2006). However, the compatibility between the two fields of expertise is rare, particularly when it comes to problems related to the integrity and stability of the immobilised biological molecules. Obvious examples of this bottleneck are the recurrent difficulties in spotting biological probes on a surface and subsequently processing this surface with bonding or activation techniques: assembly efficiency, components alignment, biomolecules degradation, etc. (Liu et al. 2000; Raj et al. 2009; Sia and Whitesides 2003)

In order to overcome these issues we have been recently developing the "adhesive microarray" approach (Corgier et al.) to provide a robust and adaptable solution for reliable diagnostic devices. For that purpose, a pressure sensitive adhesive (PSA) was used as a flat support for spotting (up to 2500 spots per $\mathrm{cm}^{2}$ density) and immobilization of biomolecules (either protein or DNA probes). The adhesive property of the support was also advantageously used for the direct assembling with 3D structures such as 
polymer or glass microfluidic networks and widespread 96-well bottomless microplates. In the present report we have been extending the concept, pushing spotting limits by generating microarrays into 384-well and 1536-well microtiter plates. It is worth to mention that generating microarrays of biomolecules inside microwells in 384 or 1536-well format remains so far extremely challenging with the currently available spotting devices. The solution proposed in this article copes easily with this issue by spotting on a flat surface before assembling of the microarrays with the bottomless well plate. Such demonstration study not only proves the adaptability of the technique but also opens the path to Ultra-HighThroughput microarray assays.

We have also been challenging the concept in term of applications fields and demonstrated the compatibility of the adhesive support with i) localised cell culture onto spotted adhesion proteins, ii) fluorescent labelling and microscopic imaging of living cells, iii) immobilisation of peptide or active antibodies and iv) detection of target molecules in complex matrices such as human blood sera. In the particular case of immunotesting, the study focused on liver diseases diagnosis and more particularly on the detection of either one liver cancer marker, the alpha-fetoprotein, or the detection of Hepatitis C Virus infection.

\section{Materials and methods}

\subsection{Materials}

Synthetic oligonucleotide probes and primers were supplied by Eurogentec (Belgium). The synthetic oligonucleotides used as a probe/target model were $\mathrm{NH}_{2}$ TTGAGGTGCATGTTTGTGCC, biotinGGCACAAACATGCACCTCAA and biotin - $\mathrm{d}(\mathrm{T})_{22}$. Peptides (Supplementary data, Table 1) derived from HCV were synthesised with a $\mathrm{NH}_{2}$ terminus modified with three lysines and three $\beta$-alanines by Altergen (Bischheim, France). Alkaline phosphatase-labelled streptavidin and the ready-to-use solution of 5-bromo-4-chloro-3indolyl phosphate and nitrobluetetrazolium (BCIP/NBT) were purchased from SigmaAldrich (Lyon, France). Mouse anti-alpha fetoprotein monoclonal antibody (6F4 clone) was obtained from AntibodyShop (Copenhagen, Denmark). Rabbit anti-alpha fetoprotein polyclonal antibody was purchased from Thermo Scientific (Rockford, USA). Alkaline phosphataselabelled anti-human $\operatorname{IgA}+\mathrm{G}+\mathrm{M}$ antibodies developed in goat and alkaline phosphataseconjugated AffiniPure Goat anti-rabbit IgG were supplied by Jackson Immuno-Research (Suffolk, UK).

Human alpha fetoprotein (AFP) was supplied by Biorbyt (Cambridge, UK). Human blood sera from healthy donors $(\mathrm{n}=5)$, AFP characterised patients $(n=8)$ and $\mathrm{HCV}$ infected patients $(n=10)$ were obtained from the Centre Hospitalo-Universitaire-Grenoble (La Tronche, France) and stored at $-20^{\circ} \mathrm{C}$.

\subsection{Spotting procedure}

For oligonucleotide microarrays preparation, the $5^{\prime}$-amino modified probes were prepared in acetate buffer $\left(0.1\right.$ mol. $\mathrm{L}^{-1}, \mathrm{KCl} 0.1 \mathrm{~mol} . \mathrm{L}^{-}$ ${ }^{1}$, bromophenol blue $0.5 \mathrm{mg} \cdot \mathrm{mL}^{-1}, \mathrm{pH}$ 5.5) to reach a final concentration of $50 \mu \mathrm{mol} . \mathrm{L}^{-1}$.

For peptides and antibodies microarray, the biomolecules were prepared in acetate buffer (0.1 mol.L $\mathrm{L}^{-1}, \mathrm{KCl} 0.1 \mathrm{~mol} . \mathrm{L}^{-1}$, bromophenol blue $0.5 \mathrm{mg} \cdot \mathrm{mL}^{-1}, \mathrm{pH} 5.5$ ) to reach a final concentration of $500 \mu \mathrm{gl} . \mathrm{L}^{-1}$.

These solutions were spotted onto TKL adhesive substrates (AXO Science, Lyon, France) at particular drop volume and pitch using a piezoelectric spotter (sciFLEXARRAYER S3, SCIENION, Germany). The substrate was air-dried at room temperature and was then ready to be assembled with bottomless microtiter plates (96, 384 or 1536-well from Greiner bio-one SAS (Courtaboeuf, France)). Videos of the spotting and assembly procedure can be seen in Supplementary Materials - Video 1 and 2.

\subsection{Oligonucleotide assay}


Oligonucleotide assays were carried out using a protocol involving the following steps. i) Wells were saturated with LowCross Buffer (Candor Bioscience, Wangen, Germany). ii) After proper dilution, samples were transferred to the wells and incubated for 30 minutes at $37^{\circ} \mathrm{C}$. iii) The wells were then loaded with the alkaline phosphatase-labelled streptavidin solution $\left(2 \mu \mathrm{g} . \mathrm{mL}^{-1}\right)$ and incubated for 30 minutes at $37^{\circ} \mathrm{C}$ ). iv) Finally, BCIP/NBT substrate solution was added in each well for signal generation. The microtiter plate bottom was imaged using a Colorimetric Image Reader (CLAIR, Sensovation, Germany) and analysed using the AXOware 1.3.7 automated software. The signal intensity per spot was calculated as the median intensity for all pixels included in a circular feature defining the spot and corrected using a local background evaluation.

The reagent or sample volume at each step depended on the plate format. For 384-well plate, washing and saturation volume were $100 \mu \mathrm{L}$ whereas incubation and detection volume were $25 \mu \mathrm{L}$. For 1536-well plate, washing and saturation volume were $10 \mu \mathrm{L}$ whereas incubation and detection volume were $5 \mu \mathrm{L}$. The total assay time was 90 minutes whatever the assay format.

\subsection{Sandwich assay}

Sandwich assays for AFP detection were carried out on an EVO75 robot (TECAN, Switzerland) equipped with a heater. For all experiments, the protocol involved the following steps; i) Wells were saturated with LowCross Buffer (Candor Bioscience, Wangen, Germany); ii) After proper dilution with anti-AFP (from Thermo Scientific, Rockford USA) at a concentration of $2 \mu \mathrm{g} \cdot \mathrm{mL}^{-1}$, samples were transferred to the wells and incubated for 30 minutes at $37^{\circ} \mathrm{C}$. iii) The wells were then loaded with the alkaline phosphatase-labelled streptavidin solution $\left(2 \mu \mathrm{g} \cdot \mathrm{mL}^{-1}\right)$ and incubated for 30 minutes at $37^{\circ} \mathrm{C}$ ). iv) Finally, $100 \mu \mathrm{L}$ of BCIP/NBT substrate solution were added in each well and incubated 30 minutes for signal generation. iv) Wells were washed with PBS after incubation, labelling and signal generation steps. The microtiter plate bottom was imaged using a Colorimetric Image Reader (CLAIR, Sensovation, Germany) and analysed using the AXOware 1.3.7 automated software. The signal intensity per spot was calculated as the median intensity for all pixels included in a circular feature defining the spot and corrected using a local background evaluation.

\subsection{Antibody binding assay}

Antibody binding assays for $\mathrm{HCV}$ infection detection were carried out on an EVO75 robot (TECAN, Switzerland) equipped with a heater. For all experiments, the protocol involved the following steps; i) Wells were saturated with LowCross Buffer (Candor Bioscience, Wangen, Germany); ii) After proper dilution with LowCross Buffer, samples were transferred to the wells and incubated for 30 minutes at $37^{\circ} \mathrm{C}$. iii) The wells were then loaded with the alkaline phosphatase-labelled anti-human $\operatorname{IgA}+\mathrm{G}+\mathrm{M}$ solution $\left(2 \mu \mathrm{g} \cdot \mathrm{mL}^{-1}\right)$ and incubated for 30 minutes at $37^{\circ} \mathrm{C}$ ). iv) Finally, $100 \mu \mathrm{L}$ of BCIP/NBT substrate solution were added in each well and incubated 15 minutes for signal generation. iv) Wells were washed with PBS after incubation, labelling and signal generation steps. The microtiter plate bottom was imaged using a Colorimetric Image Reader (CLAIR, Sensovation, Germany) and analysed using the AXOware 1.3.7 automated software. The signal intensity per spot was calculated as the median intensity for all pixels included in a circular feature defining the spot and corrected using a local background evaluation.

\subsection{Cell line culture}

Fluorescent HeLa cell lines (EGFP-HeLa) were obtained by stable transfection of the pEGFP-C1 vector (Clontech, Heidelberg, 
Germany) using lipofectamine reagent from life/technologies/Invitrogen

(Cergy Pontoise, France) and following a previously published protocol (Mandon et al. 2005). This EGFP constitutive expression vector contains the neomycin phosphotransferase gene for selection of stably transfected clones. EGFP-HeLa cells were grown on Petri dishes in DMEM (Dulbecco's Modified Eagle's Medium) from Invitrogen/GibcoBRL (Cergy Pontoise, France) supplemented with $10 \%$ foetal calf serum (FCS) from Dutscher (Brumath, France), 1 mg. $\mathrm{mL}^{-1}$ Fungizone, 50 u. $\mathrm{mL}^{-1}$ Penicillin / Streptomycin from Invitrogen/GibcoBRL (Cergy Pontoise, France) and 500 mg.mL ${ }^{-1}$ Geneticin from Invitrogen/GibcoBRL (Cergy Pontoise, France) to maintain the selection of integrated transgenic plasmid at $37^{\circ} \mathrm{C}$, in humidified atmosphere containing $5 \%$ of $\mathrm{CO}_{2}$.

After two days of cell culture, HeLa cells were seeded as to obtain approximately $6.10^{5}$ cells per $\mathrm{mL}(100 \mu \mathrm{L}$ per well $)$.

\section{Results}

The "adhesive microarray" concept was initially developed for the production of cost efficient high-throughput tools compatible with industrial processes and requirements. Spotting the arrays on a flat surface and being able to subsequently assemble them with any bottomless recipient has brought numerous new avenues for diagnostic tools development. In our previous reports we proved the ability of the system to generate sensitive genotyping assays (Corgier et al.) in 96-well format and to be the most adapted support, when compared to polystyrene or nitrocellulose membrane, for the achievement of densitometric microarrays (Le Goff et al.).

For the present study we have been challenging the concept by pushing further the throughput capabilities of the system. Figures 1-a and 1-b (real colour images obtained thanks to the presence of bromophenol blue in the spotting solution) depict the images of the spotted patterns useful for the assembly with 384 and 1536well, respectively. As can be seen, the maximum number of spots per well is 100 for the 384-well and 25 for the 1536-well, giving in both cases a total of 38400 spots per microplate. An image of a completely spotted 384-well, before assembly, plate is given in Supplementary data Figure S1. This obvious flexibility of the technology, which allows the adjustment of the compartmentalization level while keeping a high degree of screening (38400 data points per plate), is one of the key properties of the technology. The 25-plex in 1536-well plates is particularly interesting for multiplexed sandwich immunoassays, where a high degree of multiplexing is not easily achievable due to cross reaction eventualities growing exponentially with the number of immune couples engaged (Pla-Roca et al. 2012).

Figures 1-c and 1-d present closer views of a single well for the 384-well format and four adjacent wells for the 1536-well format, respectively. As a matter of fact high reproducibility and alignment of the spot were obtained, giving the possibility to assemble the spotted adhesive support with $3 \mathrm{D}$ structures bearing feature as small as 1.5 mm (1536-well inner dimension). 


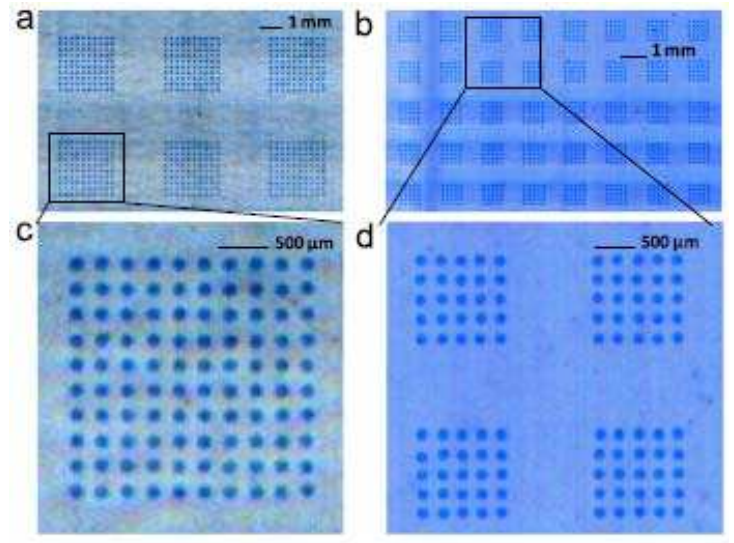

Fig. 1. Flatbed scanner images of "adhesive microarrays" spotted for the assembly with 384 (a and c) and 1536-well (b and d) plates. Images in real colour taken before assembly.

\subsection{Oligonucleotide target detection}

In order to verify that hybridisation assays can be performed directly in the assembled 384 and 1536-well plates, 384 and 1536 microarrays composed of one target sequence (TTGAGGTGCATGTTTGTGCC, $50 \mu \mathrm{M}$ ), one positive control (spotted alkaline phosphatase labelled streptavidin, $500 \mu \mathrm{g} / \mathrm{mL}$ ) and one negative control (Bovine Serum Albumin, $500 \mu \mathrm{g} / \mathrm{mL}$ ) were prepared. The principle of the colorimetric hybridization assay is the following. Samples containing biotinylated target oligonucleotides are hybridised on the microarray and the labelled with streptavidin-alkaline phosphatase conjugate (SAV-AP). The alkaline phosphatase-streptavidin system enables a colorimetric detection of hybridization: the immobilised enzyme's reaction with its substrate (BCIP/NBT) generates a purple precipitate on hybridised spots.

Typical densitometry images of the processed microarrays are presented in Figure 2 together with the target sequence dose response curves obtained using each format. For each format the limit of detection was $30 \mathrm{pM}$ (calculated for a signal to noise ratio value of 3 ) with a detection ranging over two decades at least. The hybridisation of a noncomplementary sequence (biotin-d $(\mathrm{T})_{22}$ ) did not generate any signal, validating the specificity of the assay (red circle and square in Figure 2-b and 2-d).

The performances of the assay using these 384 and 1536 formats, when compared to the 96-well format previously published by our group, appear shifted to the higher target concentrations by a decade at least (Le Goff et al.). This effect of the incubation volume reduction was already demonstrated in microsystems and shown to be possibly overcome by using an efficient dynamic incubation (Cretich et al. 2011); this might be one of the future developments of the method.

\subsection{Antibody binding assay}

In order to carry on with the challenge of the technique using different applications, we have been designing a microarray of peptides ( 20aa) bearing epitopes of various regions of the Hepatitis $\mathrm{C}$ Virus (HCV) proteins to determine antibody profiles from serum of infected patients. The test was then dedicated to the detection of specific human antibodies developed following the infection by HCV. Five HCV peptides (see Supplementary data, Table 1) were selected from a previous study (Cherif et al. 2006) to include different viral proteins. Peptides were grafted in quadruplicate on a chip together with a two control proteins (BSA and human IgG). In order to build antibody reactivity profile, sera from non infected donors $(\mathrm{n}=5)$ and $\mathrm{HCV}$ infected patients $(\mathrm{n}=10)$ were analysed at different dilution using the multiparametric peptide assay.

As shown in Figure 3, three different profiles were identified, which can be used to easily characterise patient antibodies. The first one corresponds to non infected donors (Figure 3-c), among which only very low non-specific signals were obtained except for C20 and NS4. This profile enables the determination of 
positivity thresholds of each peptide for the

infected patients (mean signal $+3 \mathrm{SD}$ ).
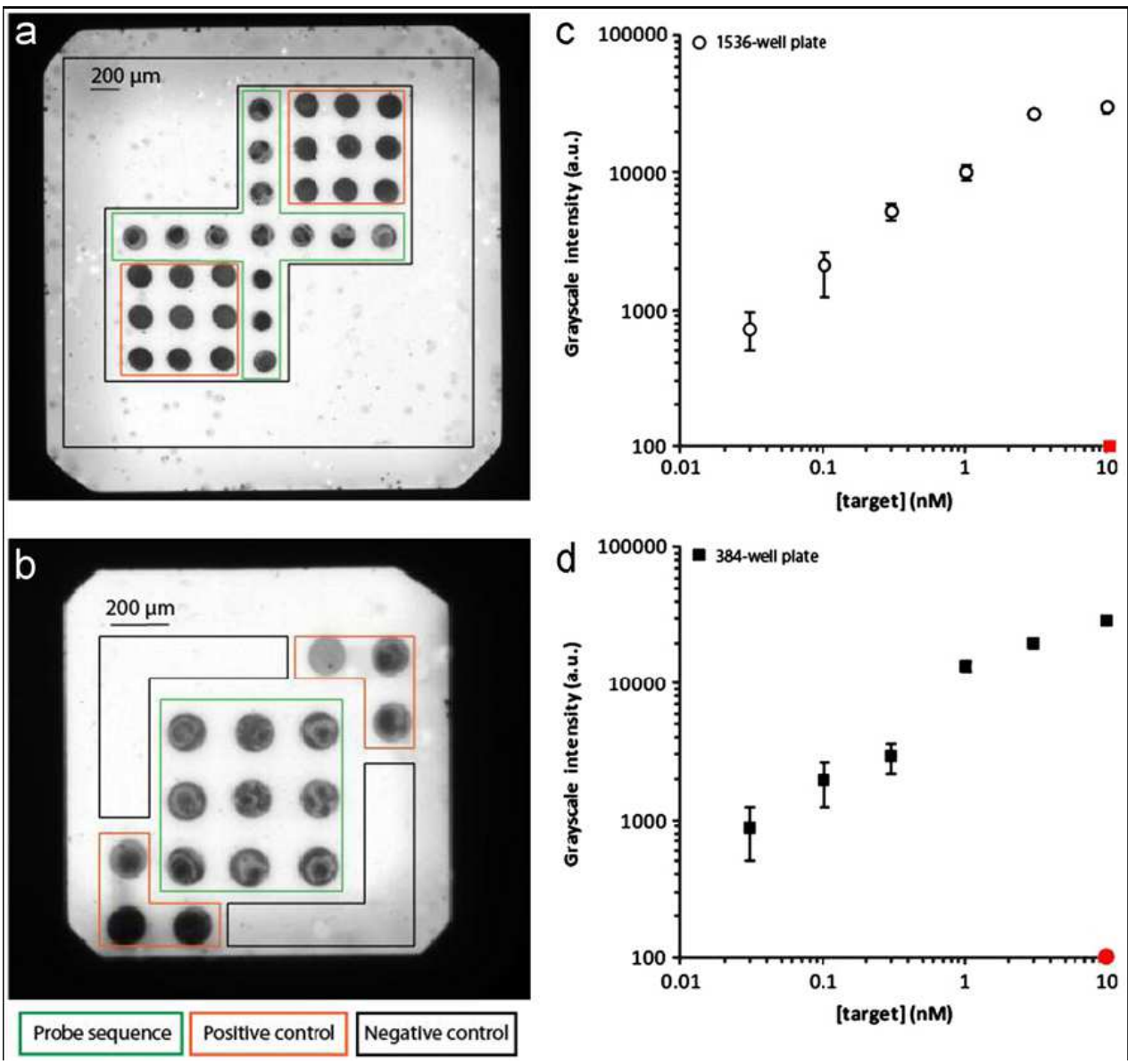

Fig. 2. Densitometry images of (a) one processed well from a 384-well plate and (b) one processed well from a 1536-well plate. Target concentration: $3 \mathrm{nM}$. Dose response curves for the detection of the target sequence using (c) a 384-well plate and (d) a 1536-well plate. Red circle and square correspond to the hybridisation of a $10 \mathrm{nM}$ noncomplementary sequence. (For interpretation of the references to colour in this figure legend, the reader is referred to the web version of this article.)

The second and third profiles (Figure 3-a and $-b$ ) are characteristic of two groups of infected patients having different antiHCV antibody specificities. The first group (Figure 3-a) is positive on all epitopes (signals above positivity threshold) while the second (Figure 3-b) is positive only for C20, NS4 and NS5. Thus, even if these differences of sera reactivity cannot be linked to clinical or infection history yet, the analytical potentialities of using a multiparametric approach is here once again clearly demonstrated (Desmet et al.
2011). Indeed, when using single probes, such as $\mathrm{C} 1$ or $\mathrm{C} 2$ peptide probes only, to detect HCV infection, half of the infected patients are identified as false negatives. Moreover, only the use of multiple probes enables the precise description of the patients' antibody reactivity and their classification within distinct groups which might have different infection history and be infected by different HCV genotypes. Exhaustive antibody profiling would be an added value for diagnosis and prognosis to treatment responses. 
a

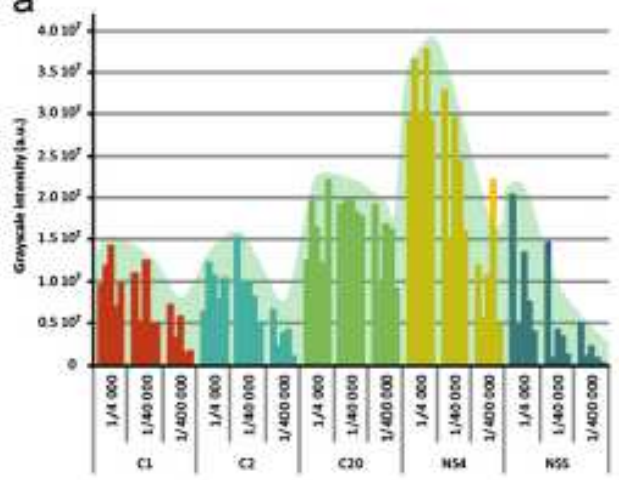

C

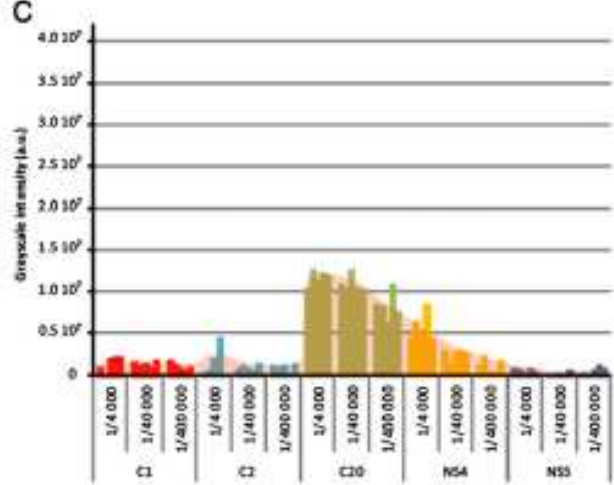

b

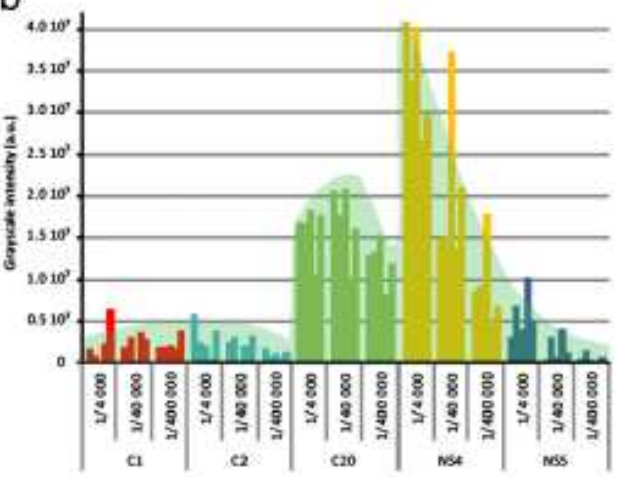

d

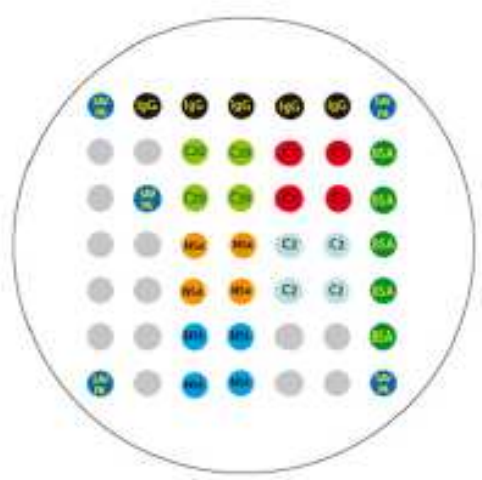

Fig. 3. Reactivity profiles of mono-infected ( $a$ and $b$ ) and healthy patient (c) using the peptide microarray (d). For each serum, three dilutions were tested: 1:400, 1:4000 and 1:40000.

\subsection{AFP sandwich assay}

The measurement of alpha-fetoprotein (AFP) in the serum is a standard for the follow up of liver diseases and hepatocarcinogenesis (Bruix and Sherman 2005; Lok et al. 2010). It was demonstrated that AFP serum concentration increases above the cut off value of 500 ng. $\mathrm{mL}^{-1}$, in parallel with hepatocyte regeneration and liver tumour size. In some cases, AFP level can be related to stages of $\mathrm{HCV}$ infection (Cedrone et al. 2000) and can be a valuable parameter to estimate the response to viral treatment (Abdoul et al. ; Lok et al. 2010). Therefore, we selected AFP in the objective of demonstrating the possibility to immobilise active antibodies on adhesive support. 96 AFP specific microarrays (Figure 4-b) were spotted and assembled with a bottomless 96-microwell plate. On a single plate, a complete AFP calibration curve was performed together with the characterisation of 8 patient sera. After colorimetric images acquisition, a calibration curve was built from the quantification of the spot median greyscale values obtained in the presence of different concentrations of the target protein. The four-parameter logistic fitting of the curve (see Supplementary data Table 2) enabled the determination of a limit of detection of $2.06 \mathrm{ng} \cdot \mathrm{mL}^{-1}$. This four-parameter fitting also permitted the back calculation of AFP in real samples without any pre-treatment or dilution. Figure 4-a presents the comparison between the results obtained in 8 samples from patients using the present method or the classical TRACE (Time Resolved Amplified Cryptate Emission, Kryptor automate) method. A good correspondence was obtained between the two methods with a coefficient of correlation of 0.864 . 


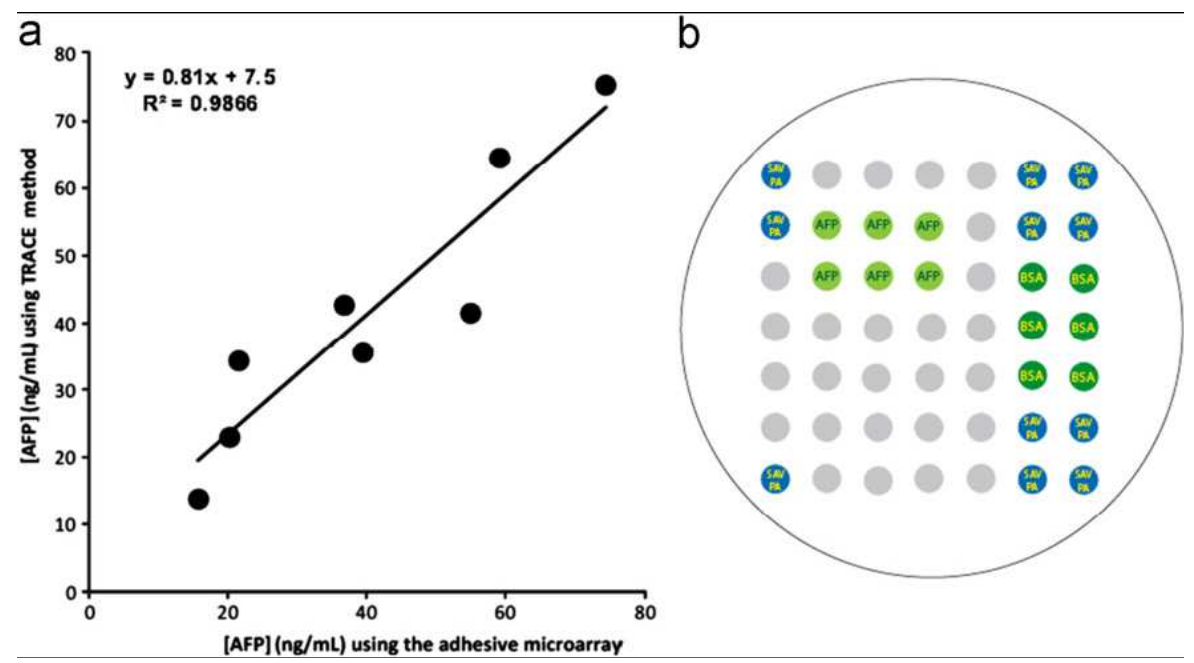

Fig. 4. (a) Graphical comparison between the results obtained in 8 samples from patients using the adhesive microarray method (triplicate assay) and the classical Time Resolved Amplified Cryptate Emission (TRACE, Kryptor automate) method. (b) The used microarray.

\subsection{Localised cell culture}

A last study was performed to demonstrate the possibility of localised culture of living cell onto our "adhesive microarray". Indeed, cell based sensors for cytotoxicity assays and drug discovery are expected to become interesting alternative of in vitro cell culture experiments. Nevertheless, the immobilisation of cells following specific patterns at the micro- and nano-scale level remains a major challenge for the development of efficient cell based arrays (Falconnet et al. 2006; Hufnagel et al. 2009; Pappas and Wang 2007; Wang et al. 2007). Immobilising cells in an organised manner brings the advantage of automated observation possibilities, especially using the 96-well plate format (Azioune et al. 2009) and thus open HTS possibilities. For this purpose, extracellular matrix proteins, such as fibronectin, laminin or collagen are often used as intermediate to attach cells on dedicated surfaces.

Using the "adhesive microarray" production technique and a 96-well format, we have designed a 49-spot microarray composed of 25 cell adhesion spots of fibronectin/BSA-FITC and 24 control spots of BSA-FITC. BSA-FITC was used both to permit the visualisation of the spot and to facilitate the homogeneous spotting of fibronectin (Heyries et al. 2009). In addition, a fluorescent cell line was used here to conveniently visualise adherent cells by avoiding immuno-staining.

Figure 5-a depicts images of the spots just after deposition. Round shaped spots of BSA-FITC and fibronectin/BSA-FITC are clearly observable using white light or fluorescent illumination under the microscope. (Supplementary data Figure S2). Spots are reproducible and each protein spot is $150 \mu \mathrm{m}$ in diameter.

Cells were then grown in the well containing the microarrays and adherent cells were observed on the fibronectin spots after 2 hours (Figure 5-b), while no adherent cells were observed on the control BSA spots (data not show). Figure 5-g also shows that allowing the initial cell culture to grow 3.5 hours instead of 2 hours before washing led to a complete coverage of the spot with cells.

The good adhesion contrast between bare support and fibronectin spots was also demonstrated by the easy removal of unattached cells by simple culture medium replacement (Figure 5-c). Pictures d, e and $f$ show the evolution of adherent cells on a single spot during 48 hours. As can be seen, cells exhibit a classical attachment 


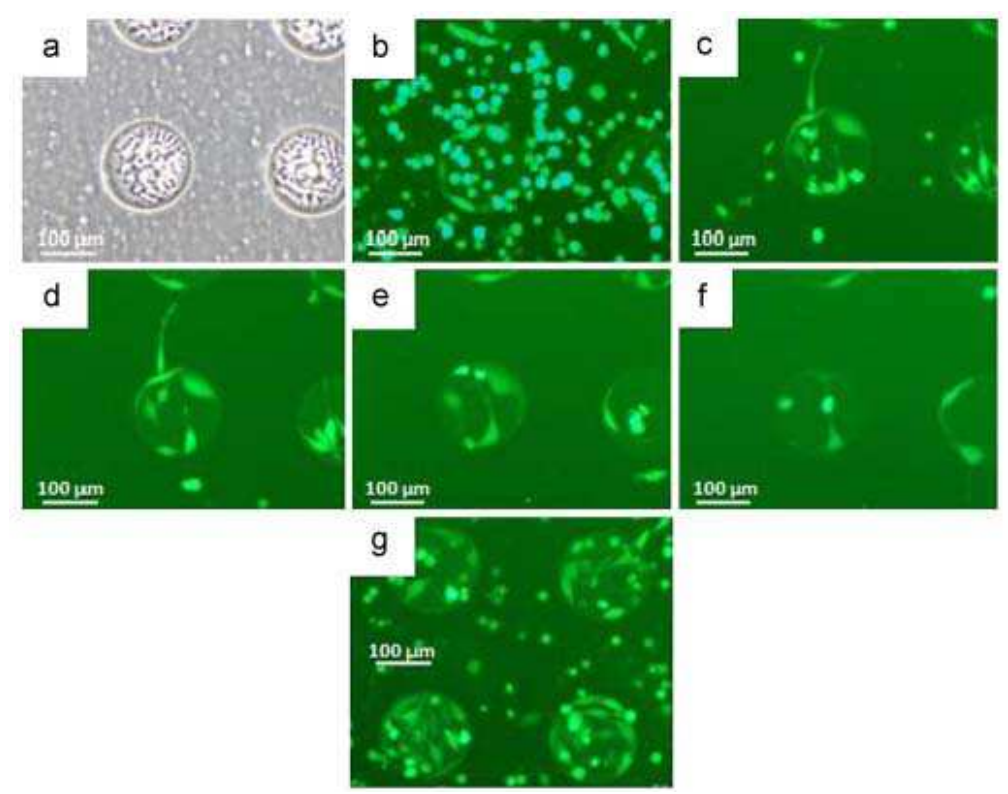

Fig. 5. (a) Optical micrograph of BSA-FITC/fibronectin spots on adhesive surface $\left(t^{1 / 40}\right)$. HeLa modified cells (expressing intracytoplasmic GFP) are then grown in the wells containing the microarrays ( $100 \mathrm{~mL}$ and 6.105 cells $\mathrm{ml}\urcorner 1)$. Images (b)-(f) show the evolution of cells on a single spot: (b) fluorescent image after $2 \mathrm{~h}$, (c) fluorescent image after $3.5 \mathrm{~h}$ and rinsing of the well, (d) fluorescent image after $20 \mathrm{~h}$, (e) fluorescent image after $21.5 \mathrm{~h}$ and washing, (f) fluorescent image after $48 \mathrm{~h}$ and (g) fluorescent image after $3.5 \mathrm{~h}$ without washing.

shape and remain fixed on fibronectin spots for the time of the experiment.

\section{Conclusion}

The TKL Adhesive technology has been evaluated on a wide range of assay types and formats, demonstrating its flexibility. Both the multiplex degree (number of spots per well) and the number of wells per plate can be tuned to perfectly match the needs of the experiment. It clearly brings advantages of both concepts: HTS or compartmentalised/parallelised assays.

Additionally, a large set of applications can be built up since proteins or oligonucleotides can be immobilised as microarrays inside the wells, and sandwich immunoassays, DNA assays, or cells assays are achievable using the adhesive technology. Interestingly, in any application the background signal coming from potential unspecific adsorption of molecules on the adhesive is extremely low.

The use of adhesive substrate dramatically simplifies the manufacturing process and decreases the cost of the system. These properties are unique in the field of microarrays and we believe that such a technology will facilitate multiplexed and/or HTS experiment future developments. Specifically, for bottomlesswell plates, the TKL adhesive microarray technology avoids the use of sealant, superstructure, clips, and tricky steps, giving an advantage to the present approach when compared to bottom glass spare products such as NEXTERION ${ }^{\circledR}$ Plate E MPX-96 from Schott or MatriPlate $^{\mathrm{TM}}$ from Matrical Biosience. Based on this technology, large scale studies involving multiplex characterisation are currently under development. 


\section{Acknowledgement}

This work is part of a project named HiFi Assays (ANR 2010 Biot 003 01), supported by the "Agence Nationale de la Recherche" and the "Lyon Biopole". The authors warmly acknowledge Candice Trocmé (IBP, CHU-Grenoble) and JeanPierre Zarski (DiGiDUNE, CHUGrenoble) for patient samples and clinical advice, Kevin Boissin for technical assistance.

\section{References}

Abdoul, H., Mallet, V., Pol, S., Fontanet, A., PLOS ONE 3(6), e2391.

Azioune, A., Storch, M., Bornens, M., Thery, M., Piel, M., 2009. Lab Chip 9(11), 1640-1642. Bruix, J., Sherman, M., 2005. Hepatology 42(5), 1208-1236.

Cedrone, A., Covino, M., Caturelli, E., Pompili, M., Lorenzelli, G., Villani, M., Valle, D., Sperandeo, M., Rapaccini, G., Gasbarrini, G., 2000. Hepatogastroenterology 47(36), 16541658.

Cherif, B., Roget, A., Villiers, C.L., Calemczuk, R., Leroy, V., Marche, P.N., Livache, T., Villiers, M.B., 2006. Clin Chem 52(2), 255-262.

Corgier, B.P., Mandon, C.A., Le Goff, G.C., Blum, L.J., Marquette, C.A., 2011. Lab Chip 11(17), 3006-3010.

Cretich, M., Bagnati, M., Damin, F., Sola, L., Chiari, M., 2011. Anal Biochem 418(1), 164166.

Desmet, C., Le Goff, G.C., Bres, J.C., Rigal, D., Blum, L.J., Marquette, C.A., 2011. Analyst 136(14), 2918-2924.
Falconnet, D., Csucs, G., Michelle Grandin, H., Textor, M., 2006. Biomaterials 27(16), 30443063.

Heyries, K.A., Mandon, C.A., Ceriotti, L., Ponti, J., Colpo, P., Blum, L.J., Marquette, C.A., 2009. Biosens Bioelectron 24(5), 1146-1152.

Hufnagel, H., Huebner, A., Gulch, C., Guse, K., Abell, C., Hollfelder, F., 2009. Lab Chip 9(11), 1576-1582.

Le Goff, G.C., Corgier, B.P., Mandon, C.A., De Crozals, G., Chaix, C., Blum, L.J., Marquette, C.A., 2012. Biosensors and Bioelectronics(In press).

Liu, X.-h., Wang, H.-k., Herron, J.N., Prestwich, G.D., 2000. Bioconjug Chem 11(6), 755-761. Lok, A.S., Sterling, R.K., Everhart, J.E., Wright, E.C., Hoefs, J.C., Di Bisceglie, A.M., Morgan, T.R., Kim, H.-Y., Lee, W.M., Bonkovsky, H.L., Dienstag, J.L., 2010. Gastroenterology 138, 493-497.

Mandon, C.A., Diaz, C., Arrigo, A.P., Blum, L.J., 2005. Biochem Biophys Res Commun 335(2), 536-544.

Pappas, D., Wang, K., 2007. Anal. Chim. Acta 601(1), 26-35.

Pla-Roca, M., Leulmi, R.F., Tourekhanova, S., Bergeron, S., Laforte, V., Moreau, E., Gosline, S.J.C., Bertos, N., Hallett, M., Park, M., Juncker, D., 2012. Mol Cell Proteomics In press.

Raj, J., Herzog, G., Manning, M., Volcke, C., MacCraith, B.D., Ballantyne, S., Thompson, M., Arrigan, D.W.M., 2009. Biosens. Bioelectron. 24(8), 2654-2658.

Sia, S.K., Whitesides, G.M., 2003.

Electrophoresis 24(21), 3563-3576.

Wang, Z., Kim, M.-C., Marquez, M., Thorsen, T., 2007. Lab. Chip 7(6), 740-745.

Whitesides, G.M., 2006. Nature 442(7101), 368-373. 


\section{Supplementary data}

Table S1: Sequences of peptides used in this study.

\begin{tabular}{cccc}
\hline Origin & Peptide* & Position\# & Sequence \\
\hline C1 & $1-20$ & MSTNPKPQRKTKRNTNRRPQ \\
HCV & C20 & $10-29$ & KTKRNTNRRPQDVKFPGGGQ \\
& NS4/4 & $1711-1731$ & QDVKFPGGGQIVGGVYLLPRR \\
& NS5/2 & $2284-2309$ & CASHLPYIEQGMQLAEQFKOK \\
& & AMPIWARPDYNPPLLESWKDPDYVPP
\end{tabular}

${ }^{*} \mathrm{C}=$ core; $\mathrm{NS}=$ non structutal polypeptides of the Hepatitis $\mathrm{C}$ Viral (HCV) polyprotein.

\# Amino acid position of the peptide within the HCV polyprotein.

Table S2: AFP calibration curve four-parameter fitting curves coefficients.

\begin{tabular}{lll}
\hline General equation & \multicolumn{3}{l}{ Coefficients } \\
\hline & A & $1.93 \mathrm{e}+2$ \\
$\mathrm{y}=\mathrm{D}+(\mathrm{A}-\mathrm{D}) /\left(1.0+(\mathrm{x} / \mathrm{C})^{\mathrm{B}}\right)$ & $\mathrm{B}$ & 1.38 \\
& $\mathrm{C}$ & $7.09 \mathrm{e}+1$ \\
& $\mathrm{D}$ & $9.03 \mathrm{e}+1$ \\
& RMSE & 12.02 \\
$\mathrm{R}^{2}$ & 0.912 \\
\hline
\end{tabular}




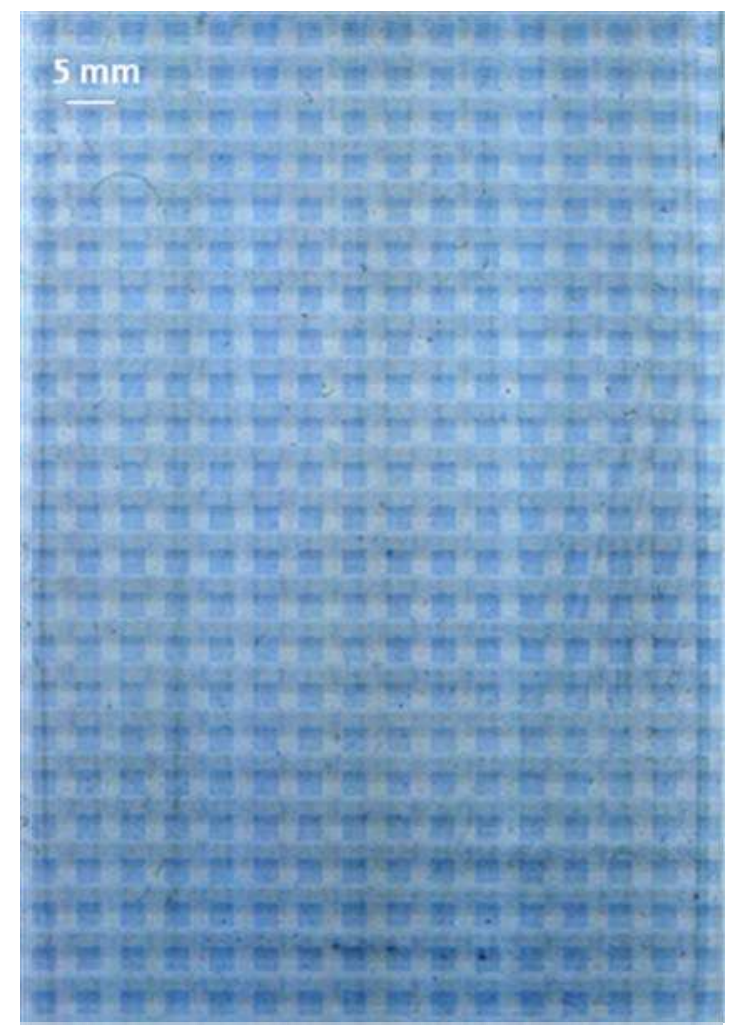

Figure S1 384 matrices of 100 spots each spotted to fit a 384-well bottomless plate. Image taken before the assembly. 

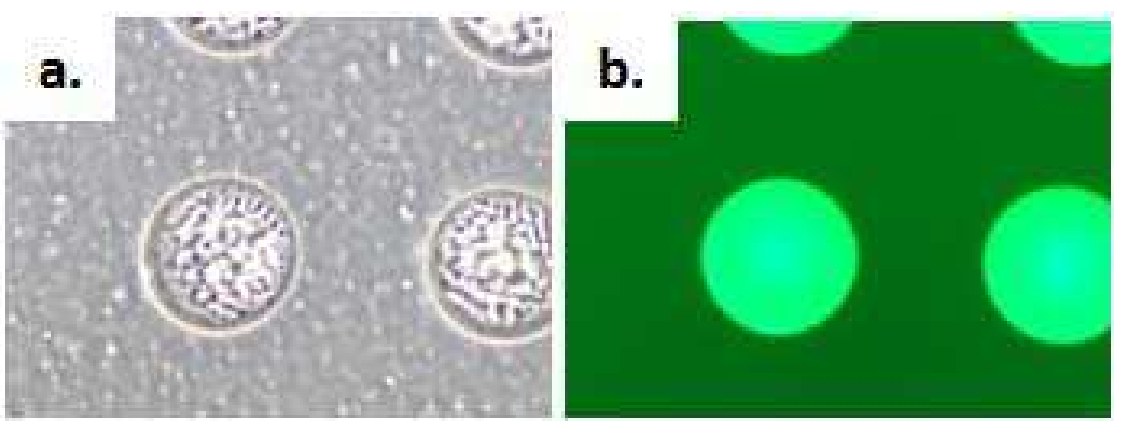

Figure S2 White light (a) and fluorescent (b) images of BSA-FITC/fibronectin spots. 